\title{
Plasma presepsin level is an early diagnostic marker of severe febrile neutropenia in hematologic malignancy patients
}

Yusuke Koizumi ${ }^{1,2 *}$, Kaoru Shimizu ${ }^{3}$, Masayo Shigeta ${ }^{3}$, Takafumi Okuno ${ }^{2}$, Hitoshi Minamiguchi ${ }^{2}$, Katsuyuki Kito $^{2}$, Keiko Hodohara ${ }^{2}$, Yuka Yamagishi ${ }^{1}$, Akira Andoh², Yoshihide Fujiyama ${ }^{2}$ and Hiroshige Mikamo ${ }^{1}$

\begin{abstract}
Background: Febrile neutropenia (FN) is a common infectious complication in chemotherapy. The mortality of FN is higher in hematologic malignancy patients, and early diagnostic marker is needed. Presepsin is a prompt and specific marker for bacterial sepsis, but its efficacy in severe febrile neutropenia (FN) is not well confirmed. We tried to clarify whether it is a useful maker for early diagnosis of FN in patients during massive chemotherapy.

Methods: We measured plasma presepsin levels every 2-3 day in FN cases and evaluated its change during the course of massive chemotherapy. The patients had hematologic malignancy or bone marrow failure, and in all cases, neutropenia was severe during the episode. The baseline levels, onset levels, increase rate at FN onset, and onset / baseline ratio were evaluated for their efficacy of early FN diagnosis.

Results: Eleven episodes of bacteremia (six gram negatives and five gram positives) in severe neutropenia were analyzed in detail. While plasma presepsin level was strongly associated to the CRP level $(r=0.61, p<0.01)$, it was not associated with the absolute WBC count $(r=-0.19, p=0.19)$, absolute neutrophil count $(r=-0.11, p=0.41)$ or absolute monocyte count $(r=-0.12, p=0.40)$. The average of onset presepsin level was $638 \pm 437 \mathrm{pg} / \mathrm{mL}$ and the cutoff value $(314 \mathrm{pg} / \mathrm{mL})$ has detected FN onset in 9 of 11 cases. The two cases undetected by presepsin were both Bacillus species bacteremia.

Conclusions: Plasma presepsin level is a reliable marker of FN even in massive chemotherapy with very low white blood cell counts. Closer monitoring of this molecule could be a help for early diagnosis in FN. But bacteremia caused by Bacillus species was an exception in our study.
\end{abstract}

Keywords: Presepsin(soluble CD14-ST), Febrile neutropenia, Bacteremia, Chemotherapy, CD14

\section{Background}

Patients with hematologic malignancies often suffer from severe infections. The malignancies themselves are disorders of immune systems, and chemotherapy further causes febrile neutropenia (FN). Some patients die of infection in spite of immediate antimicrobial treatment. In acute myeloid leukemia, for example, the incidence of

\footnotetext{
* Correspondence: ykoizumi@aichi-med-u.ac.jp

'Department of Clinical Infectious Diseases, Aichi Medical University, 1-1 Yazakokarimata, Nagakute, Aichi 480-1195, Japan

2Department of Gastroenterology and Hematology, Shiga University of Medical Science, Otsu 520-2192, Japan

Full list of author information is available at the end of the article
}

chemotherapy associated infectious toxicities is as high as $64 \%$, and the mortality is higher than $10 \%$ [1]. There have been many approaches, including biomarkers, to improve the prognosis of FN. But still, it is difficult to predict or to detect those malicious events in the earliest time.

Presepsin (soluble CD14 subtype) is a novel biomarker of sepsis. It is useful in early diagnosis, and it can also be a prognostic marker of severe sepsis [2-6].

While this molecule is a prompt and specific marker for bacterial infections, its reliability in FN is not yet confirmed. Especially, massive chempotherapy causes 
severe cytopenia including CD14 expressing neutrophils or monocytes. Because presepsin derives from CD14 [7], severe neutropenia can cause false-negativity of this molecule.

Thus, we conducted a simple study of plasma presepsin measurements to find answer to two practical questions;

1) Does presepsin rise in bacteremia cases even in the setting of severe neutropenia?

2) Is plasma presepsin level a useful maker for early diagnosis of FN?

\section{Methods}

\section{Study population}

This study was conducted in Shiga University of Medical Science Hospital, from May 2014 to October 2014.

During the period, plasma samples were collected from hematologic malignancy and bone marrow failure patients under chemotherapy. The patients received conventional induction chemotherapy or hematopoietic stem cell transplantation (HSCT) and all of them experienced severe neutropenia.

We evaluated the plasma presepsin levels in febrile neutropenia group (FN group). And we compared the values with those of control cases, afebrile neutropenia group (AFN group).

We defined two groups as follows;

1) FN group patients are those diagnosed of bacteremia during neutropenic period (WBC count less than $1,000 / \mu \mathrm{L}$ or neutrophil count less than $500 / \mu \mathrm{L}$ ). Pathogens were identified in blood cultures and patients were treated with appropriate antimicrobial therapy.

2) AFN group patients were those who had no febrile episodes for 3 weeks after chemotherapy. They received no antimicrobials during the course.

\section{Plasma presepsin level measurement}

We made regular blood examination every 2-3 day (approximately on days 1,3,5,8,10,12 and 15) of chemotherapy. After centrifugation within $2 \mathrm{~h}$ after phlebotomy, the plasma was preserved in $-80{ }^{\circ} \mathrm{C}$ till measurement.

Plasma presepsin level was measured by a rapid chemiluminescent enzyme immunoassay on the fully automated PATHFAST $^{\circledast}$ immunoanalyzer (Mitsubishi Chemical Medience Corporation, Tokyo, Japan) [8]. We defined the cut-off value $314 \mathrm{pg} / \mathrm{mL}$ according to manufacturer's instruction.

\section{Evaluation}

We evaluated serial change in plasma presepsin levels at regular intervals.
Specifically, the value obtained on day -1 to 1 of chemotherapy was defined as baseline level. We defined the first day of fever onset $\left(\geq 38.0{ }^{\circ} \mathrm{C}\right)$ as the "onset day". Blood culture was routinely obtained within \pm 1 day of fever onset.

The "onset plasma presepsin level (onset level)" was defined as the result on the day of fever and blood culture positivity.

And the presepsin increase rate (IR) was defined as

$$
\operatorname{IR}(\%)=\frac{\{(\text { onset level })-(\text { previous level })\} /(\text { previous level }) \times 100}{\text { Blood examination interval }}
$$

The onset levels within one episode, presepsin IR around the day of febrile neutropenia onset, and onset / baseline ratio were evaluated.

\section{Statistical analysis}

We performed Student's $t$-test for comparisons of two independent groups of sampled data. The data were expressed as mean \pm standard deviation. $P$ values of $<0.05$ were considered evidence of a significant difference.

The linear dependence between the two variables was assessed by Pearson's product-moment coefficient. $\mathrm{R}$ and Rho values $\geq 0.7$ were considered to define a strong correlation between variables, respectively. And $\mathrm{R}$ and Rho ranging between 0.69 and 0.5 and 0.49 to 0.3 were considered to define moderate and low correlation, respectively.

We analyzed data using the statistical software JMP 10 (SAS Institute Inc., Cary, NC, USA).

\section{Results}

Patient background (Table 1)

Table 1 shows the patient characteristics.

There were five myeloid diseases, including three acute myeloid leukemia (AML), 1 myelodysplastic syndrome (MDS) RAEB2, and 1 severe aplastic anemia (AA).

Other five cases were lymphoid diseases, including two malignant lymphoma (ML), two multiple myeloma (MM), and one acute lymphoid leukemia (ALL).

All the cases were on chemotherapy; six on induction therapy, three on myeloablative conditioning regimen for hematopoietic stem cell transplantation, and one on consolidation therapy. All the regimens had potentials of severe myelosuppression.

The Nadir WBC count during the chemotherapy was $0-100 / \mu \mathrm{L}$ in nine out of ten cases. There were no cases with severe renal failure.

\section{Episodes of febrile neutropenia (Table 1)}

Eleven episodes of febrile neutropenia were observed in ten patients; 9 with primary bacteremia, 1 with severe pneumonia, and 1 with skin \& soft tissue infection. 
Table 1 Patient characteristics

\begin{tabular}{|c|c|c|}
\hline \multirow[t]{6}{*}{ Comorbidities } & Acute myeloid leukemia & 3 \\
\hline & multiple myeloma & 2 \\
\hline & malignant lymphoma & 2 \\
\hline & acute lymphoid leukemia & 1 \\
\hline & myelodysplastic syndrome & 1 \\
\hline & aplastic anemia & 1 \\
\hline \multirow[t]{3}{*}{ chemotheapy } & induction therapy & 6 \\
\hline & $\begin{array}{l}\text { conditioning regimen } \\
\text { hematopoietic stem cell } \\
\text { transplantation }\end{array}$ & 3 \\
\hline & consolidation therapy & 1 \\
\hline \multirow{3}{*}{$\begin{array}{l}\text { Nadir WBC count during } \\
\text { the chemotherapy }\end{array}$} & $0-100 / \mu \mathrm{L}$ & 9 \\
\hline & $101-500 / \mu \mathrm{L}$ & 1 \\
\hline & $501-/ \mu \mathrm{L}$ & 0 \\
\hline \multirow[t]{3}{*}{ focus of infection ${ }^{a}$} & primary bacteremia & 9 \\
\hline & severe pneumonia & 1 \\
\hline & skin \& soft tissue infection & 1 \\
\hline \multicolumn{3}{|c|}{ pathogens identified in blood cultures } \\
\hline Gram negatives & & 6 \\
\hline K.pneumoniae & & 3 \\
\hline E.coli & & 1 \\
\hline E.aerogenes & & 1 \\
\hline B.fragilis & & 1 \\
\hline Gram positives & & 5 \\
\hline S.epidermidis & & 1 \\
\hline S.hominis & & 1 \\
\hline B.cereus & & 1 \\
\hline Bacillus sp. & & 1 \\
\hline E.gallinarum & & 1 \\
\hline days of the infection onset ${ }^{b}$ & & $11.9[3-18]$ \\
\hline $\begin{array}{l}\text { average number of the samples } \\
\text { examined for presepsin }\end{array}$ & & $6.5[4-9]$ \\
\hline
\end{tabular}

Pathogens identified in blood cultures were, six gram negative bacteria (3 Klebsiella pneumoniae, 1 Escherichia coli, 1 Enterobacter aerogenes, and 1 Bacteroides fragilis) and five gram positive bacteria (1 Staphylococcus epidermidis, 1 Staphylococcus hominis, 1 Bacillus cereus, 1 Bacillus sp., and 1 Enterococcus gallinarum).

The onset of infection was on the day 11.9 (average, range [3-18]) of chemotherapy, and 6.5 (average, range [4-9]) samples per one case were examined for plasma presepsin level.

All FN patients survived bacteremia after receiving appropriate antimicrobial agents, though one case had severe acute respiratory distress syndrome requiring intensive care.

\section{Change of plasma presepsin levels in FN cases}

Figure 1 shows the changes in plasma presepsin level over time during a chemotherapy course. All the samples measured in this study are plotted in the figure.

The average of presepsin levels in myeloid diseases $(384 \pm 369.9 \mathrm{pg} / \mathrm{mL}$ was slightly lower than that of lymphoid diseases $(384 \pm 369.9557 \pm 493.5 \mathrm{pg} / \mathrm{mL}, p$ $=0.11$, Student's t-test).

There was no significant decrease within the first week of chemotherapy, which usually causes severe neutropenia.

The lowest value was $82.6 \mathrm{pg} / \mathrm{mL}$ scored in case 8 , a multiple myeloma case, on day 8 of HSCT conditioning regimen. On that day, the patient was afebrile with WBC count of $100 / \mu \mathrm{L}$, but 4 days later, he developed bacteremia with presepsin level of $503 \mathrm{pg} / \mathrm{mL}$. The detailed trend of presepsin and CRP levels are shown in Additional file 1: Table S1.

\section{Plasma presepsin levels and other parameters}

Figure 2a shows the relationship between plasma presepsin level and white blood cell count (WBC).

Plasma presepsin level was not significantly associated with the absolute WBC count $(r=-0.19, p=0.19)$.

The median plasma presepsin level was $456.5 \mathrm{pg} / \mathrm{mL}$ in low WBC count below $100 / \mu \mathrm{L}$.

The plasma presepsin level was not associated with absolute neutrophil count $(r=-0.11, p=0.41)$ or absolute monocyte count $(r=-0.12, p=0.40)$, either. Meanwhile, plasma presepsin level was strongly associated to the CRP level $(r=0.61, p<0.01$, Fig. 2b. $)$

We also examined the association between presepsin levels and renal function.

The plasma presepsin level was not associated with serum creatitine level $(r=0.08, p=0.55)$, or estimated glomerular filtration rate (eGFR) $(r=0.21, p=0.12)$.

\section{Baseline, onset plasma presepsin levels and increase rates in $\mathrm{FN}$ cases}

Onset levels, increase rates (IR) and onset / baseline ratio of presepsin are shown in Table 2

The average baseline level was $220 \pm 83.1$ (range $106-333) \mathrm{pg} / \mathrm{mL}$ and average onset level was $638 \pm 437$ (range 217-1810) pg/mL.

In the episodes with gram negative bacteremia, onset levels were elevated beyond cut-off level in all cases (average $819 \pm 520 \mathrm{pg} / \mathrm{mL}$, range $341-1810 \mathrm{pg} / \mathrm{mL}$ ).

In the episodes with gram positive bacteremia, onset levels were elevated in 3 out of 5 cases (average $420 \pm 97.0 \mathrm{pg} / \mathrm{mL}$, range $217-644 \mathrm{pg} / \mathrm{mL}$ ). The onset presepsin levels are slightly higher in gram negative bacteremia than gram positive bactermia $(p=0.14$, Student's $t$-test). Two cases of Bacillus bacteremia (case 10,11) showed no elevation of onset presepsin levels at the onset time. 

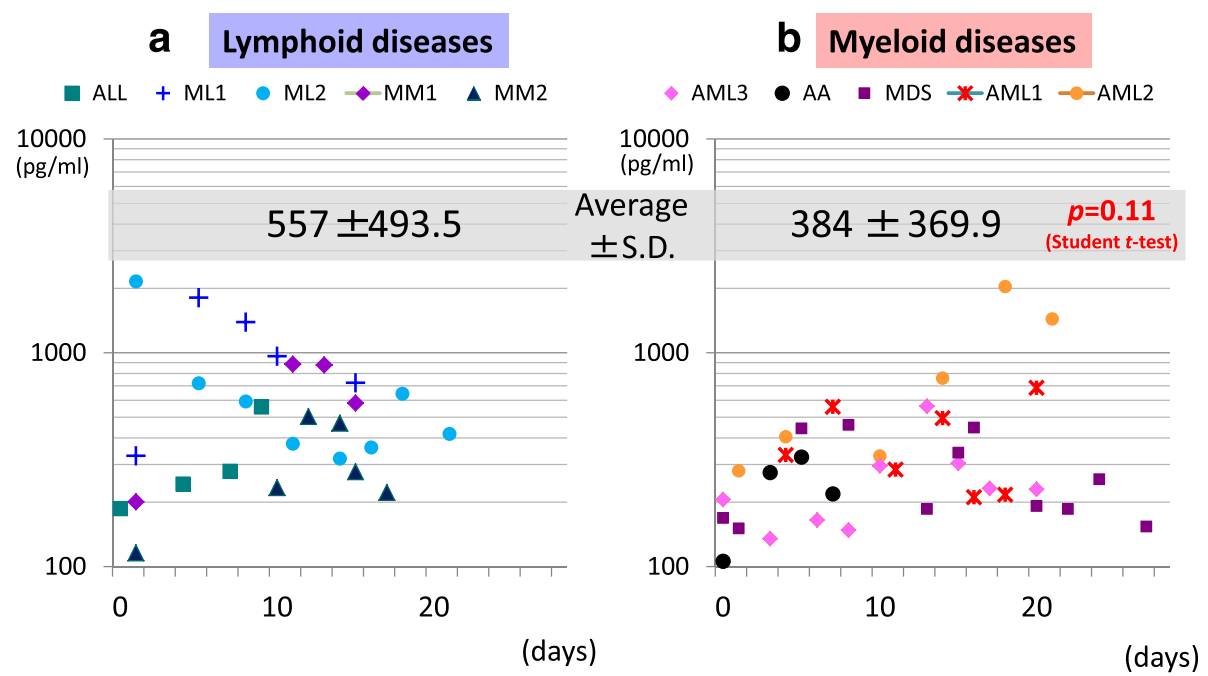

Fig. 1 Plasma presepsin level change over time and comorbidities. Changes in plasma presepsin level over time in lymphoid malignancy cases (a) and myeloid malignancy cases (b) are shown. Horizontal axis shows the day of chemotherapy. The average of plasma presepsin level was lower in myeloid malignancies. Note that most of the presepsin values are above $100 \mathrm{pg} / \mathrm{mL}$, suggesting that it maintains certain levels even in severe neutropenic state

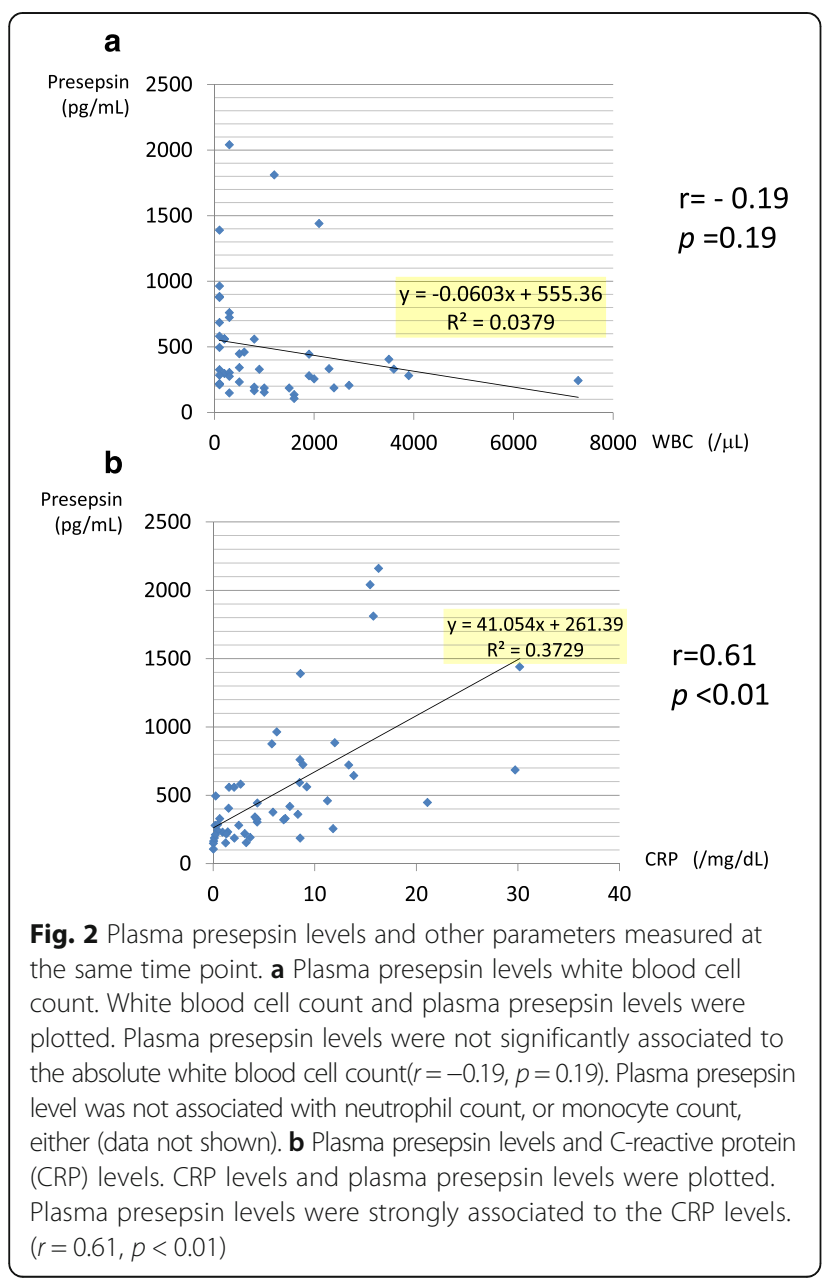

The average increase rate (IR) was 44 (range 1-112) \% and, nine out of 11 bacteremic FN cases showed IR of more than $30 \%$.

When we apply onset value $\geq 314 \mathrm{pg} / \mathrm{mL}$ and/or IR larger than $30 \%$ as positive findings, we could detect 10 out of 11 febrile neutropenia cases.

Or, onset / baseline ratio above two has detected 10 out of 11 cases.

\section{Presepsin levels in representative cases}

We show representative FN cases, demonstrating the efficacy of plasma presepsin levels in early diagnosis of septicemia.

Case 3 (Fig. 3a) shows typical clinical course of gram negative bacteremia in a case with $\mathrm{B}$ cell lineage acute lymphoid leukemia. The onset of febrile neutropenia was on day 10 of consolidation therapy. On day 9, presepsin was elevated to $558 \mathrm{pg} / \mathrm{mL}$ while CRP was within normal range at the same time. The blood culture on day 10 has detected K.pneumoniae.

Case 4 (Fig. 3b) shows the dynamics of presepsin levels in MDS case. On day 1 of chemotherapy, presepsin level was not elevated in spite of marked leukocytosis and tumor fever. On day 5, presepsin elevated and cefepime was started, and on day 8 , the patient developed methicillin resistant S.hominis bacteremia. Probably the elevation of presepsin suggested uncontrolled bacteremia with the organism resistant to cefepime. Meropenem and vancomycin was started, and soon the fever has subsided, accompanied by presepsin level decrease. One day after cessation of antibiotics, the case developed high fever due to $K$. pneumoniae bacteremia. Presepsin was measured $6 \mathrm{~h}$ prior to fever and chills, and was 


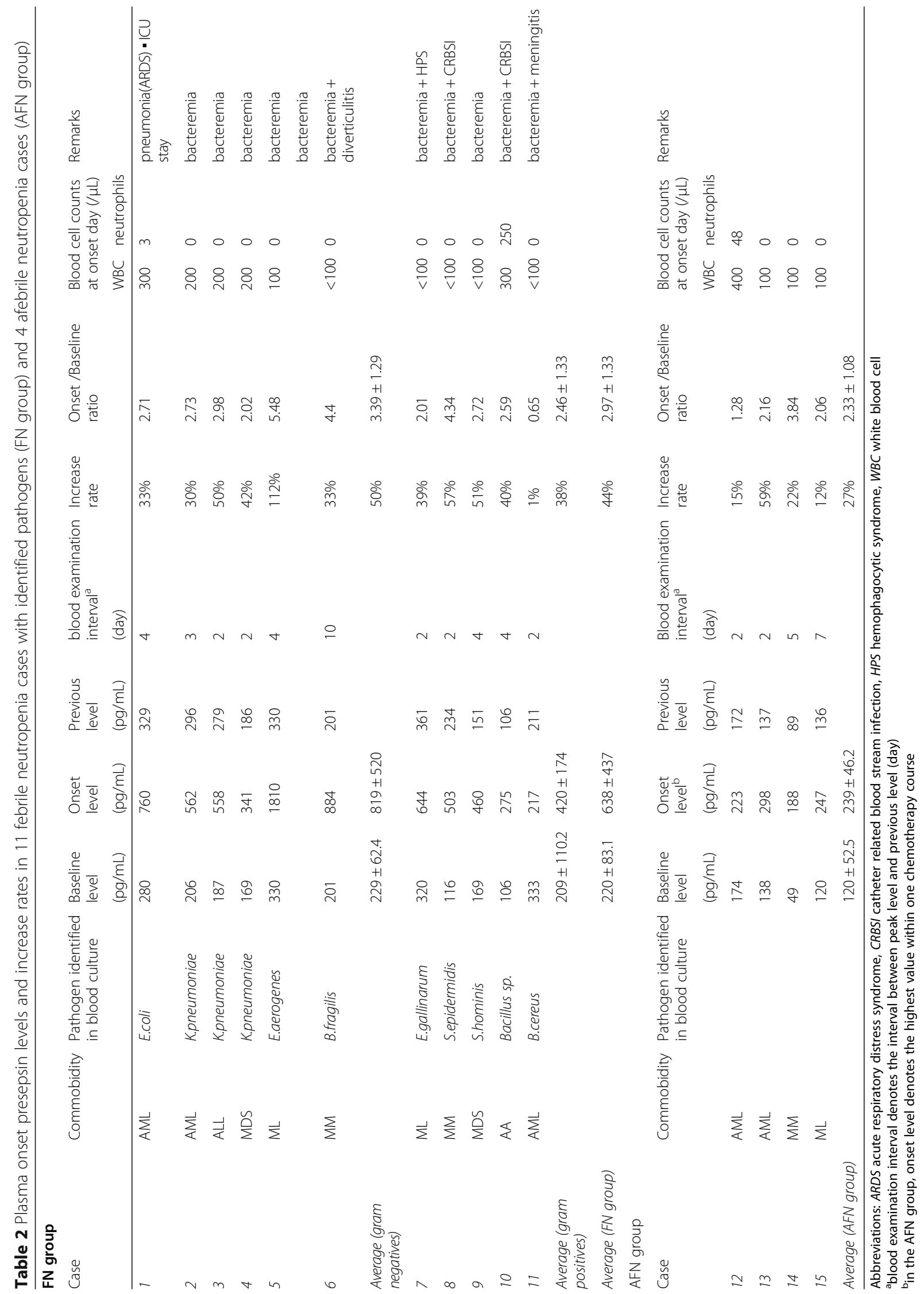




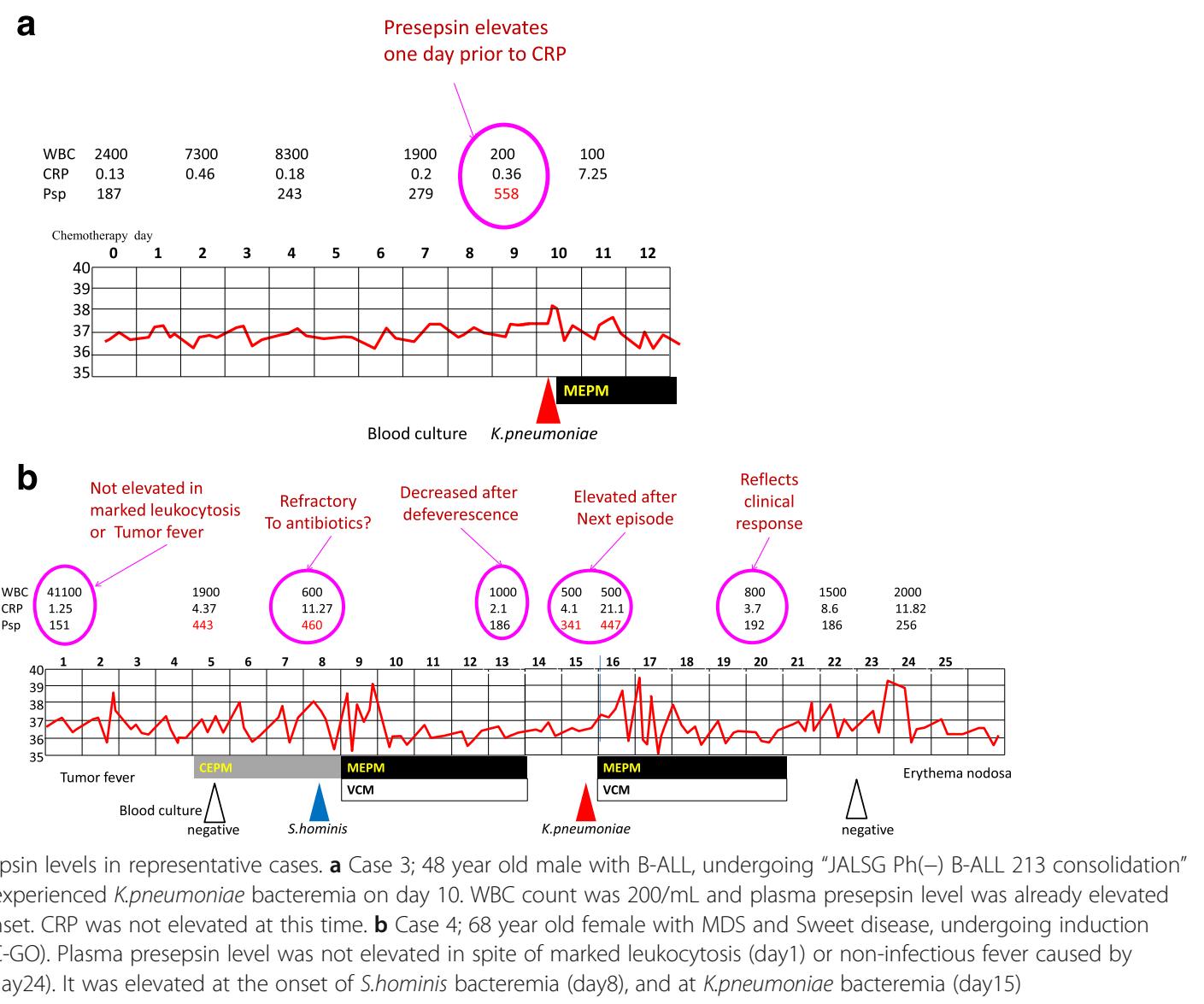

elevated again, suggesting the ability to detect infection even in an asymptomatic state. After appropriate antibiotic treatment, presepsin level was normalized again. Meanwhile, neutrophil count was below $600 / \mu \mathrm{L}$. A few days after resolution, the temperature has risen again with erythema nodosa,but presepsin level was within normal range.

In cases of Bacillus sp., plasma presepsin level was not elevated at the onset of febrile neutropenia. In both cases, presepsin level was elevated 2 days after the onset. Case 10 is the aplastic anemia patient in HSCT. He suffered from Bacillus bacteremia as blood stream infection. The onset of FN was on day 3 of chemotherapy. The presepsin level was within normal range on the onset day, but 2 days later, it has increased to $325 \mathrm{pg} / \mathrm{mL}$. Case 11 was AML patient on induction chemotherapy. On day 18 , she developed bacteremia and severe meningitis. But presepsin level was $217 \mathrm{pg} / \mathrm{mL}$. Two days later, it showed an increase to $685 \mathrm{pg} / \mathrm{mL}$.

Presepsin levels of AFN cases in comparison to FN cases Table 2 shows the result of parameters in AFN cases. As for AFN cases, the average of baseline plasma presepsin levels was $120 \pm 52.5 \mathrm{pg} / \mathrm{mL}$. There was no drastic decrease during the severe neutropenic period and none of the values was above the cut off level.

The average of all examined presepsin levels in AFN group $(n=25)$ was $162 \pm 61.7 \mathrm{pg} / \mathrm{mL}$, and it was significantly lower than that of FN group $(n=69)(451 \pm$ $304 \mathrm{pg} / \mathrm{mL}, p=0.0012$ ).

The highest levels in AFN cases were also compared with onset plasma presepsin levels of FN group.

The average of the highest presepsin levels was $239 \pm$ $46.2 \mathrm{pg} / \mathrm{mL}$ in AFN cases. It was slightly lower than in FN cases $(638 \pm 437 \mathrm{pg} / \mathrm{mL}, p=0.099$, Student's $t$-test $)$.

\section{Discussion}

Presepsin is a one of the subtypes of soluble N-terminal fragment of CD14 protein with molecular weight of $13 \mathrm{kDa}$. It is the receptor for lipopolysaccharide (LPS) / LPS -binding protein complexes [2] and is released in the early phase of infection. The molecule rises as early as within $2 \mathrm{~h}$ of inflammation onset, which is even earlier than procalcitonin, C-reactive protein (CRP) or interleukin-6 [2, 9]. Another fascinating aspect of prespsin is its high specificity for bacterial infections. Because its precursor CD14, expressed on the surface of phagocytes, is internalized during bacterial phagocytosis, 
the processed subtype presepsin has strong association with bacterial infections. Nowadays, it is well known that presepsin is a useful early diagnostic marker of sepsis. And there are reports showing its superiority to CRP in differentiating bacteremic SIRS from that of other causes [10]. Its diagnostic efficacy has been proved in various fields such as surgery, burn, neonates, and central nervous system [11-14]. However, the reliability of presepsin in febrile neutropenia has not been well demonstrated so far. Probably the fact that CD14 is expressed in neutrophils or monocytes, might pose a question against its quality, especially in a severe neutropenia after massive chemotherapy.

Our study is one of the first reports showing dynamics of plasma presepsin levels in FN cases. And we proved that 1) presepsin maintains a proper level in severe neutropenia cases, and 2) presepsin is a useful marker for early diagnosis of FN.

The most important finding in this study is that presepsin level was not associated with WBC, neutrophil, or monocyte count. The baseline and the lowest plasma presepsin levels were not extremely low as expected even in neutropenia settings. Giavarina et. al. [15] studied the presepsin levels of healthy adult controls, concluding that the reference limits for the presepsin were $55-184 \mathrm{pg} / \mathrm{mL}$ (90\% confidence intervals, CI, were 45 to 58 and 161 to 214, respectively). The lowest value in our study was $48.7 \mathrm{pg} / \mathrm{mL}$ (AFN group), which is not so low compared with those reference data. Thus we can say that presepsin maintains a proper level even in severe neutropenia cases. It might be explained by the recent finding that monocyte, rather than neutrophil, is the dominant producer of presepsin [16]. Production from tissue macrophages or resident monocytes might play a role in maintaining the plasma presepsin level.

Another result is that plasma presepsin level was significantly elevated at the early phase of most bacteremia episodes. The data have shown a clear relationship between presepsin level and CRP, suggesting its sensitivity and validity in evaluation of infection. Especially in gram negative bacteremia, it was higher than the normal range in all the cases. Various cutoff levels of presepsin has been proposed to detect bacterial infection, but in those reports, the background of the cases (Intensive care units, emergency room, or general medicine), and goals of the studies (discrimination of bacterial/non bacterial infection, or early detection of sepsis) are different. We simply applied the cutoff level as written in the manufacturer's instruction. The cutoff value of $314 \mathrm{pg} / \mathrm{mL}$ was lower than some of the reports [2-6]. We aimed to improve sensitivity rather than specificity because our goal is to detect the FN onset in the early phase and to prevent overt sepsis. However, in the two FN bacteremia cases caused by Bacillus species, presepsin level stayed within the normal range at the onset day. We could say presepsin level is not appropriate to detect early phase of Bacillus bacteremia, though the reason cannot be readily explained. Probably it might be due to the low immunogenicity by this bacterium.

The size of this study was small, and retrospective design can be a limitation. Yet, the retrospective nature of this study has four advantages at least. First, we selected cases with definite diagnosis of bacteremia and severe complications. Second, we included only the cases with severe neutropenia, whose median WBC count at FN onset were $100 / \mu \mathrm{L}$. Third, none of the cases had severe renal dysfunction which interferes to the presepsin value [17]. Fourth, the measurement of presepsin levels was made regularly, not in spot, throughout a chemotherapy course and FN episode. So we could follow up the trend from early phase to resolution of bacteremia. Many of the reports deal with mass data yielded from hundreds of patients. But detailed understanding and interpretation of clinical course of every case is also important.

\section{Conclusion}

In conclusion, plasma presepsin level is a reliable marker of FN even in extremely low WBC counts. In addition to absolute value, evaluation of increase rate can help early diagnosis of FN in both myeloid and lymphoid disorders. Closer monitoring of this molecule could prevent infection associated death in hematologic malignancy cases.

\section{Additional file}

Additional file 1: Table S1. Plasma presepsin level change over time compared with CRP in FN group (cases 1-11) and AFN group (cases 12-15). (XLSX $13 \mathrm{~kb})$

\section{Abbreviations}

AA: Aplastic anemia; AFN: Afebrile neutropenia; ALL: Acute lymphoid leukemia; AML: Acute myeloid leukemia; CRP: C reactive protein; FN: Febrile neutropenia; HSCT: Hematopoietic stem cell transplantation; IR: Increase rate; LPS: Lipopolysaccharide; MDS: Myelodysplastic syndrome; ML: Malignant lymphoma; MM: Multiple myeloma; RAEB: Refractory anemia with excessive blast; WBC: White blood cell

\section{Acknowledgements}

None to declare.

\section{Funding}

This work was not supported by any funding.

\section{Availability of data and materials}

The data and materials can be obtained on request from the authors.

\section{Authors' contributions}

YK, AA, and YF designed the study. YK, KS and MS performed the analyses. TO, HM, KK, and KH collected the data. YK, YY and HM drafted the manuscript. All authors reviewed the manuscript. All Authors read and approved the final version of this manuscript.

Competing interests

The authors declare that they have no competing interests. 


\section{Consent for publication}

We have obtained consent to publish from the participant (or legal parent or guardian for children) to report individual patient data.

\section{Ethics approval and consent to participate}

Informed consent was obtained from all patients after verbal and written information provision. Permission for this study was provided by the Institutional Ethics Committee at Shiga University of Medical Sciences.

\section{Author details}

'Department of Clinical Infectious Diseases, Aichi Medical University, 1-1 Yazakokarimata, Nagakute, Aichi 480-1195, Japan. ${ }^{2}$ Department of Gastroenterology and Hematology, Shiga University of Medical Science, Otsu 520-2192, Japan. ${ }^{3}$ Department of Laboratory Medicine, Shiga University of Medical Science, Otsu 520-2192, Japan.

Received: 18 September 2016 Accepted: 14 December 2016 Published online: 05 January 2017

\section{References}

1. Dillman RO, Davis RB, Green MR, et al. A comparative study of two different doses of cytarabine for acute myeloid leukemia: a phase III trial of cancer and leukemia group B. Blood. 1991:78:2520-6.

2. Yaegashi Y, Shirakawa K, Sato N, Suzuki Y, Kojika M, Imai S, Takahashi G, Miyata M, Furusako S, Endo S. Evaluation of a newly identified soluble CD14 subtype as a marker for sepsis. J Infect Chemother. 2005;11(5):234-8.

3. Shozushima T, Takahashi G, Matsumoto N, Kojika M, Okamura Y, Endo S. Usefulness of presepsin (sCD14-ST) measurements as a marker for the diagnosis and severity of sepsis that satisfied diagnostic criteria of systemic inflammatory response syndrome. J Infect Chemother. 2011;17(6):764-9.

4. Endo S, Suzuki Y, Takahashi G, Shozushima T, Ishikura H, Murai A, Nishida T, Irie Y, Miura M, Iquchi H, Fukui Y, Tanaka K, Nojima T, Okamura Y. Usefulness of presepsin in the diagnosis of sepsis in a multicenter prospective study. J Infect Chemother. 2012:18(6):891-7.

5. Ulla M, Pizzolato E, Lucchiari M, Loiacono M, Soardo F, Forno D, Morello F, Lupia E, Moiraghi C, Mengozzi G, Battista S. Diagnostic and prognostic value of presepsin in the management of sepsis in the emergency department: a multicenter prospective study. Crit Care. 2013;17(4):R168.

6. Masson S, Caironi P, Fanizza C, Thomae R, Bernasconi R, Noto A, Oggioni R, Pasetti GS, Romero M, Tognoni G, Latini R, Gattinoni L. Circulating presepsin (soluble CD14 subtype) as a marker of host response in patients with severe sepsis or septic shock: data from the multicenter, randomized ALBIOS trial. Intensive Care Med. 2015:41(1):12-20.

7. Bufler P, Stiegler G, Schuchmann M, Hess S, Krüger C, Stelter F, Eckerskorn C, Schütt C, Engelmann H. Soluble lipopolysaccharide receptor (CD14) is released via two different mechanisms from human monocytes and CD14 transfectants. Eur J Immunol. 1995;25(2):604-10.

8. Okamura Y, Yokoi H. Development of a point-of-care assay system for measurement of presepsin (sCD14-ST). Clin Chim Acta. 2011;412(23-24): 2157-61.

9. Chenevier-Gobeaux C, Bardet V, Poupet H, Poyart C, Borderie D, Claessens YE. Presepsin (sCD14-ST) secretion and kinetics by peripheral blood mononuclear cells and monocytic THP-1 cell line. Ann Biol Clin (Paris). 2016;74(1):93-7.

10. Romualdo LG, Torrella PE, González MV, Sánchez RJ, Holgado AH, Freire AO, Acebes SR, Otón MD. Diagnostic accuracy of presepsin (soluble CD14 subtype) for prediction of bacteremia in patients with systemic inflammatory response syndrome in the Emergency Department. Clin Biochem. 2014;47(7-8):505-8.

11. Novelli G, Morabito V, Ferretti G, Pugliese F, Ruberto F, Venuta F, Poli L, Rossi M, Berloco PB. Pathfast presepsin assay for early diagnosis of bacterial infections in surgical patients: preliminary study. Transplant Proc. 2013;45(7): 2750-3.

12. Cakır Madenci Ö, Yakupoğlu S, Benzonana N, Yücel N, Akbaba D, Orçun Kaptanağası A. Evaluation of soluble CD14 subtype (presepsin) in burn sepsis. Burns. 2014;40(4):664-9.

13. Pugni L, Pietrasanta C, Milani S, Vener C, Ronchi A, Falbo M, Arghittu M, Mosca F. Presepsin (Soluble CD14 Subtype): reference ranges of a New sepsis marker in term and preterm neonates. PLoS One. 2015;10(12): e0146020.
14. Stubljar D, Kopitar AN, Groselj-Grenc M, Suhadolc K, Fabjan T, Skvarc M. Diagnostic accuracy of presepsin (sCD14-ST) for prediction of bacterial infection in cerebrospinal fluid samples from children with suspected bacterial meningitis or ventriculitis. J Clin Microbiol. 2015;53(4):1239-44.

15. Giavarina D, Carta M. Determination of reference interval for presepsin, an early marker for sepsis. Biochem Med (Zagreb). 2015;25(1):64-8.

16. Arai Y, Mizugishi K, Nonomura K, Naitoh K, Takaori-Kondo A, Yamashita K. Phagocytosis by human monocytes is required for the secretion of presepsin. J Infect Chemother. 2015;21(8):564-9.

17. Nakamura Y, Ishikura H, Nishida T, Kawano Y, Yuge R, Ichiki R, Murai A. Usefulness of presepsin in the diagnosis of sepsis in patients with or without acute kidney injury. BMC Anesthesiol. 2014;14:88.

\section{Submit your next manuscript to BioMed Central and we will help you at every step:}

- We accept pre-submission inquiries

- Our selector tool helps you to find the most relevant journal

- We provide round the clock customer support

- Convenient online submission

- Thorough peer review

- Inclusion in PubMed and all major indexing services

- Maximum visibility for your research

Submit your manuscript at www.biomedcentral.com/submit
Biomed Central 